
N. Dlodlo
M. Dhurup

\title{
BARRIERS TO E-MARKETING ADOPTION AMONG SMALL AND MEDIUM ENTERPRISES (SMES) IN THE VAAL TRIANGLE
}

\author{
Ms. N. Dlodlo: Faculty of Management Sciences, Vaal University of Technology \\ Prof. M. Dhurup: Faculty of Management Sciences, Vaal University of Technology
}

Synopsis

Purpose: The purpose of the study is to complement existing literature by examining the relevant barriers contributing to the nonadoption of electronic marketing practices by SMEs in the Vaal Triangle.

Methodology: Primary data was collected using a quantitative research technique with the use of a structured questionnaire as the survey instrument. A total of 168 businesses were selected randomly and visited within the various municipal areas in the Vaal Triangle. These businesses were visited between August and November 2008. Thirty-two small, medium and medium enterprises SMEs refused to participate resulting in 123 usable questionnaires for the purposes of the analysis. Factor analysis was used to examine the robustness of the factor structure using principal component analysis.

Findings: A five-dimensional structure was established comprising a 16 item-scale. The major impediments towards the nonadoption of e-marketing include technology incompatibility with target markets, lack of knowledge, stakeholder unreadiness, technology disorientation and technology perception. The reliability analysis, reflected coefficient values ranging from 0.70 to 0.88 indicating satisfactory internal consistency amongst variables within each dimension.

Implications: By analysing the barriers that inhibit the adoption of e-marketing strategies among SMEs, marketers are presented with recommended strategies and implications on how to approach the challenges presented by Internet technological advancements. Internet capacities of SMEs may be strengthened through nurturing e-marketing awareness and providing adequate information tools through diverse Internet Marketing training programmes.

Originality/Value: SMEs can prove to be a major source of economic growth for many African countries if sufficient guidance and support on how best to overcome the challenges of adopting advanced marketing practices is available.

Keywords: E-marketing, SMEs, barriers, non-adoption, factor analysis.

\section{INTRODUCTION}

Owing to the low growth rate of global economies, high unemployment and an unsatisfactorily high level of poverty in countries, the creation of the small and medium sized business sector plays a critical role in economic growth (Vuuren \& Groenewald, 2007:269). The SME sector remains one of the most promising economic sectors contributing approximately $30 \%$ of the gross domestic product (GDP) in South Africa and over $80 \%$ in global economies (Jutla, Bodorick \& Dhaliwal, 2002:139). Cronje, Du Toit and Motlatla (2004:6) affirm that SMEs act as a catalyst for economic growth as well as for the development of the arts, human resources, manufacturing and sport sectors. In line with the August report from the Parliamentary Monitoring Group (RSA, 2009), economies can benefit from the build-up of efficient SMEs in order to facilitate the government's plans to create about half a million jobs for South Africans targeted originally for accomplishment by the end of the year, 2009. In this regard, uptake of Internet marketing strategies has the potential to contribute to the exponential growth of the SME sector. However, despite its potential as a marketing tool, actual use of e-marketing has not met expectations (Elliot \& Boshoff, 2007:16).

Marketers are able to identify and satisfy customer needs and preferences through monitoring website visitations, e-mails, online surveys and chat rooms conducted on the Internet (Porter, 2001:68). Business 
enterprises can develop custom-made products and services that meet the precise needs of consumers and this in turn culminates in high returns for businesses (Zhao, 2005:56). The adoption of e-marketing enables businesses to promote their products and services to the public through advertisements, banner advertisements, e-mails and mobile phone competitions (Chaffey \& Smith, 2005:12). Businesses are also better able effectively to serve global markets and to distribute goods and services to customers globally through e-marketing adoption (Harris \& Dennis, 2002:18).

This article reviews the relevant literature on the importance of the SME sector, e-marketing and the barriers to e-marketing adoption. In addition, the generic problems regarding the adoption of e-marketing are highlighted.

\section{THE SME SECTOR AND ITS IMPORTANCE}

Small enterprises comprise between five and 100 formally employed persons. Employees are employed on a full-time basis. According to the Department of Trade and Industry, a small business is owner managed; registered with local authorities and business activities are conducted from fixed premises (RSA, 2005:5). Medium enterprises constitute between 100 and 200 formal employees (Cronje et al., 2004:5). Such businesses have vast potential of growing into large businesses, should capital injections be obtained. Often they are characterised by a decentralisation of power to a new management layer (Falkena, 2000:25-27) between the SME operator and employees.

SMEs are considered the "lifeblood of modern economies" (Rao, Metts \& Monge, 2003:13), creating far more jobs than those created by large businesses, contributing 37 percent to employment in South Africa (Soontiens, 2002:712; Barry \& Milner, 2002:316). SMEs provide a variety of goods and services for customers to choose from, some of which might otherwise not be provided by large businesses (Jackson, 2004:6). SMEs act as catalysts for economic growth as well as for the development of the arts, human resources, manufacturing and sport sectors (Cronje et al., 2004:6). Studies conducted by Moodley (2002:37) from a development perspective reported that SMEs are important because of their potential for job creation and distribution of wealth which results in a multiplier effect on the socio-economic activities of a country which in turn creates a multiplier effect on the socio-economic developmental activities of a country (Wrycza \& Gajda, 2007).

SMEs are flexible and can also act as subcontractors to most large enterprises in the economy, ultimately leading to equitable distribution of income (Lloyd 2002:8). The Department of Trade and Industry report (RSA:1995) indicates that SMEs provide personalised services and also make a positive contribution to wealth creation in the South African economy. They are breeding incubators for entrepreneurial talent and a testing ground for new products (Chaston, 2000:74). They are agents of change, widely facilitating innovation and competition within various national economies (Barry \& Milner, 2002:317).

This sector tends to differ from large enterprises in that they stimulate competition, bring about a diversity of products and services, have less formality in their internal and external systems and possess hands-on managerial style, which facilitates faster decision-making times (Kendall, Tung, Chua, Dennis \& Tan, 2001:225).

Despite the concerted efforts by the South African government to eliminate potential barriers to technology adoption through the liberalisation in the telecommunications sector, this growth has not significantly filtered down to the SME sector (Poon \& Swatman, 1999:9). 
The generic barriers to e-marketing adoption are discussed in the next section.

\section{E-MARKETING AND GENERIC BARRIERS TO ADOPTION}

The E-Marketing Association defines e-marketing as "the use of electronic data and applications for planning and executing the conception, distribution, promotion and pricing of ideas, goods and services to create exchanges that satisfy individual and organisational objectives" (Gohary, 2007:4). Burgess and Bothma (2007:397) define e-marketing as a "business's efforts to inform, converse, promote and sell products and services over the Internet".

In knowledge economies, high competition among profit-making businesses is of paramount importance in order to attract customers. Decision-making times and sales cycles are becoming shorter (Ryssen, 2004:48). There is also a need to keep pace with contemporary business requirements in ensuring that marketing's standing as a business essential is closely upheld by all enterprises. This background explains why it is that SMEs should integrate Internet-driven marketing principles into their mainstream business practices.

A review of literature reveals that the adoption of e-marketing varies by industry type (Poon \& Swatman, 1999:14) with the public, education and charity organisations being the lowest adopters of Internet technology (Maguire, Koh \& Magrys, 2007:39). Global adoption of e-marketing by SMEs has been slowest in the agricultural sector (Sparkes \& Thomas, 2001:332). This refutes earlier research findings of Teo and Tan (1998:342) who found that no significant relationship exists between industry sector and adoption of emarketing.

Businesses in the services sector, primarily the consultancy and professional services, have reported a robust interest in adopting Internet technologies for marketing purposes as their type of business integration necessitates the use of computer technologies as a core activity (Coviello, Brodie, Brookes \& Palmer, 2004:15). Websites in the airline, hospitality, software and electronics industries indicate that the adoption of the Internet has been extensive in these sectors (Kalyanam \& Mclntyre, 2002:468). SMEs specialising in manufacturing products are less likely to adopt Internet technologies as compared with knowledge intensive service organisations such as consultancies (Martin \& Matlay, 2001:403; Sadowski, Maitland \& Dongen, 2001:90). A majority of manufacturing SMEs are still in the lower stages of e-business adoption because these firms perceive very low levels of benefit from e-business (Ramsey \& Ibbotson 2006:317). Technologyintensive industries have reaped the rewards of Internet technology, which are yet to be experienced by traditional marketers (Chan \& Swatman, 2000:72). These high-tech firms constitute early adopters of Internet technologies (Fillis, Johannson \& Wagner, 2004:182). This is contrary to studies undertaken by Matlay and Addis (2003:323) who assert that there is no connection between Internet adoption and technological content of a business environment.

If a firm has inadequate security procedures or an unrecognised brand name this could jeopardise customers' confidence in the usefulness of the Internet as a trading platform (Durkan, Durkin \& Dillen, 2003:101). This is because any online research and purchasing decisions are made solely based on trust (Wagener 2004:39). Inadequate security measures, expertise and financial means to guard against unauthorised access to confidential information by employees and from outsiders and hackers pose a hindrance to Internet adoption (Khan 2007:24-25; Walczuch, Braven \& Lundgren, 2000:566).

E-marketing leads to standardisation of products and prices as differences among competitors' products are reduced (Porter, 2001:73). Large firms are also able to encroach onto niche markets, which were traditionally serviced by SMEs because e-marketing significantly reduces transaction costs (Jeffcoat, Chappell \& Feindt, 
2002:124). These limitations on the part of SMEs have contributed to the significantly low levels of emarketing adoption. However, the turning point comes when marketers out-compete each other based on information and service quality (Hamill, 1997:306; Elliot \& Sewry, 2006:43).

Drew (2003:86) makes the point that the costs of infrastructure, access and adoption of e-marketing have declined to levels where these no longer present a barrier. Adoption is often impeded by information barriers such as uncertainties with respect to the performance of the Internet or the future development of these technologies, within the SME context (Hollenstein, 2004:321).

Some SMEs occupy small niches in the local markets where 'word of mouth' is a guarantee for quality such that the adoption of Internet for marketing purposes may be viewed as an inhibitor for their business communications (Taylor \& Murphy, 2004:285).

\section{PROBLEM STATEMENT}

The Internet is the fastest growing technology in the world, taking approximately seven years to reach a $25 \%$ market share from its conception, as opposed to the telephone that took 35 years, and the television, which took 26 years (Singh, 2002:3). There is little evidence of long-term strategic development of e-marketing technologies within SMEs (Fillis et al., 2004:180). Only 17 percent of the SMEs in South Africa believe that electronic business transactions are critical to their operations (Zaayman, 2003:2). From these current users, considerable variations still exist in their adoption of e-marketing. Some owners of very small businesses may adopt e-marketing as a means of defending their autonomy in business and thus adopt the technologies in a casual and ad hoc manner (Gilmore, Gallagher \& Henry, 2007:234). This is the current scenario despite ample evidence to suggest that e-marketing can facilitate improved business practices particularly within the small and medium sized business fraternity (Whiteley, 2000:217). Several barriers have been cited in the literature as contributing largely to the non-adoption of e-marketing strategies.

Some small firms may be resistant to embrace online technologies due to perceived risks that include privacy and security issues (Liebermann \& Stashevsky, 2002:291). A research conducted in Asia highlighted that globally, SMEs are not prepared to adopt e-marketing as a serious business concept owing to the limited acceptance of online selling by consumers (Lane et al., 2004:10). Findings of Singh (2002:6) further alluded to the fact that customers are reluctant to shop online due to insufficient knowledge and limited trust in the use of credit cards as well as the issue of delivery of online purchases. However, adoption is often impeded by information barriers such as uncertainties with respect to the performance of the Internet or to the future development of these technologies globally (Hollenstein, 2004:321).

In a study carried out by Johnstone and Wright (2004:228) on the barriers affecting the implementation of Internet systems and procedures in different countries, it was revealed that the following were the rankings in order from the most prohibitive barrier to the least of barriers:

- High cost of installing infrastructure; high price of technology, large investment requirements and liquidity constraints;

- Uncertain return on investment (ROI);

- Limited worker expertise caused by a general shortage of highly skilled workers and insufficient training;

- Lack of management vision, support and enthusiasm in the adoption of Internet technology,

- Inability to outsource IT expertise; and

- Bad experiences in the past. 
However, these rankings are not consistent across countries. Further research has shown various related issues to be possible inhibitors of e-marketing adoption. Lack of training, capital and understanding of the potential benefits brought about by Internet technology have been cited as key barriers to the adoption of emarketing by SMEs (Migiro \& Adigun, 2005:70). Other studies consider the lack of knowledge as a factor made manifest in a lack of awareness; advice and support or having a staff compliment without the necessary IT skills (Stansfield \& Grant, 2003:23; Kohn \& Husig, 2006:993). SME owners pursuing unclear business strategies often contribute to their businesses losing sight of the value of adopting Internet technology (Migiro \& Adigun, 2005:70). Other researchers have highlighted the absence of a national and international regulatory framework related to privacy and security as a major concern for SMEs not adopting the Internet (Lewis \& Cockrill, 2002:199).

\section{PURPOSE OF THE STUDY}

The paper seeks to advance the findings advocated in previous studies on e-marketing barriers that exist among SMEs by establishing barriers to e-marketing using a factor analytical approach.

\section{METHODOLOGY}

To obtain an objective perspective, a literature study was conducted on barriers inhibiting the systematic adoption of e-marketing as well as an empirical investigation. Primary data was collected using a quantitative research technique with the use of a structured questionnaire as the survey instrument. The rationale for selecting a quantitative study was that it is cheaper, flexible and allows for replication of the research procedure thus enhancing validity of research findings. Quantitative studies possess the rigor and coherence that is necessary for addressing the issues and problems (Malhotra, 2004:137) that underpin the nonadoption of e-marketing by SMEs.

\section{Population and the sample}

The historical evidence approach was used to determine the sample size for this research (Zikmund, 1999:320). A sample size of 150 was set and therefore deemed appropriate and feasible for this particular study. This figure is also consistent with sample guidelines from past similar surveys conducted by Upfold and Sewry (2006:5); Beheshti and Sangari (2007:236); Uzoka, Shemi and Seleka (2007:6). The sample constituted small and medium sized businesses in the Vaal Triangle. The target population was restricted to Managers, SME owners, IT specialists, or Heads of Marketing Departments. An appropriate sampling frame was assembled from various lists that included a register from the Gauteng Enterprise Propeller (GEP), the Vaal Triangle business directory as well as SME databases from the relevant municipalities in the region. SMEs were randomly selected from the population so each population unit had an equally non-zero chance of being selected thus allowing statistical inferences to be made (Bradley, 2007:172).

\section{Data collection}

Three fieldworkers to conduct the interviews were selected by the researchers based on their ability to understand the concept of e-marketing. These students were screened and selected from a Marketing Research 4 class from a university. They were trained in various aspects of questionnaire fieldwork administration.

Pre-testing was conducted on five academics in marketing and IT fields in order to ensure that the questionnaire met expectations in providing accurate information and to assess whether or not respondents understood the questions correctly. In addition, a pilot study was conducted with 20 SMEs (10 small and 10 medium enterprises). This technique was used as an indispensable aid for developing the final questionnaire. 


\section{N. Dlodlo \\ M. Dhurup}

The views of SME operators and other researchers were taken into account prior to conducting the main survey. Suggestions were taken into account resulting in the compilation of the final measuring instrument. A survey method was used as it a satisfactory means of assessing information about a population with an ease of administration (Zikmund, 2000:220). A total of 168 businesses within the various municipal areas in the Vaal Triangle were selected randomly and visited between August and November 2008. Thirty-two SMEs refused to participate resulting in 123 usable questionnaires for the purposes of the analysis.

\section{RESULTS}

The results are described taking into account the composition of the sample in terms of small and medium enterprises, demographic analysis of the data and descriptive statistics explained by the means of the variables relating to the barriers to e-marketing adoption. Thereafter, the factor analytical procedure and extraction of factors is described.

\section{The sample composition}

A total of 115 businesses (93\%) were classified within the small sector whereas only eight firms (7\%) qualified for classification as medium enterprises based on number of employees and annual turnover as shown in Table 1 below.

Table 1 Sample composition

\begin{tabular}{|l|l|l|l|l|}
\hline Enterprise size & Number of employees & Annual turnover (rands) & Count $(\mathrm{n})$ & $\%$ \\
\hline Small & Fewer than 100 & Less than 8 Million & 115 & 93 \\
\hline Medium & Greater than 100 but less than 200 & Greater than 8 Million & 8 & 7 \\
\hline TOTAL & & 123 & 100 \\
\hline
\end{tabular}

Demographic data of the respondents was also collected including gender, age and education levels. Of the 123 businesses that were included in the survey, 77 respondents (63\%) were males and 46 respondents were females (37\%). The largest category of respondents was between 40 to 49 years which comprised 39 percent of the sample $(n=48)$. This was followed by the 30 to 39 years age group which represented $34 \%$ of the sample $(n=39)$. 15 percent of the respondents were under 30 years of age, and 12 percent fell in the 50 years and older age category. Seven out of ten standard industry classification (SIC) sectors were represented in the sample. The industry representation of the sample is reported in Figure 1. The majority of respondents comprised the community, social and personal services sectors which constituted 32 respondents (26\%). This sector comprises mostly hairdressing, medical care as well as recreational services. The wholesale, retail, clothing, hotel and restaurant business sector comprised 21 respondents (17\%) followed by the manufacturing and financial services sectors each constituting 18 respondents (15\%). The transport, storage and communication sector comprised 14 respondents $(11 \%)$ of the sample. 
Figure 1: Industry representation of sample

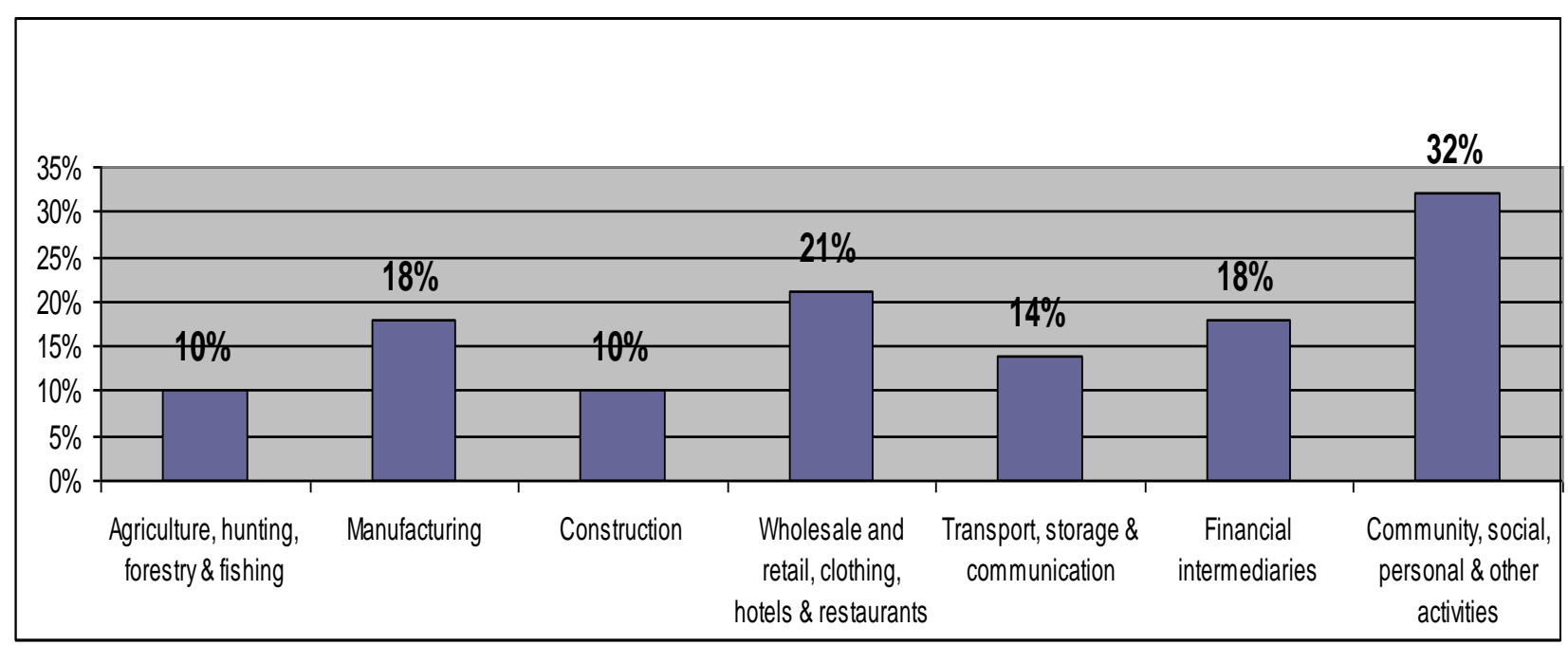

\section{Descriptive analysis on barriers to e-marketing adoption}

With the exploratory nature of the study, the data was initially analysed using descriptive statistics. Table 2 reports on e-marketing adoption barriers. On the perceptions of the barriers inherent in the implementation of various e-marketing strategies, respondents were requested to list the top five inhibitive factors of emarketing adoption. The most critical challenge facing SMEs was identified as the unavailability of resources to implement the systems. Of the 123 SMEs which were surveyed, 23 percent (28 respondents) strongly agreed and 62 percent (77 respondents) agreed to the statement that they find e-marketing too expensive to implement. Furthermore, 29 percent (35 respondents) somewhat agreed with the statement that e-marketing is a security threat to their business. Lack of knowledge,training, advice and support have also been highlighted as being major factors in the adoption process. Approximately 54 percent (67 respondents) of the SMEs cited that they do not know much about e-marketing. In the same vein, 48 percent (58 respondents) somewhat agreed that their organisations do not possess the necessary staff skills required for the complete implementation of e-marketing. 

N. Dlodlo
M. Dhurup

Table 2: Descriptive analysis - barriers to e-marketing adoption

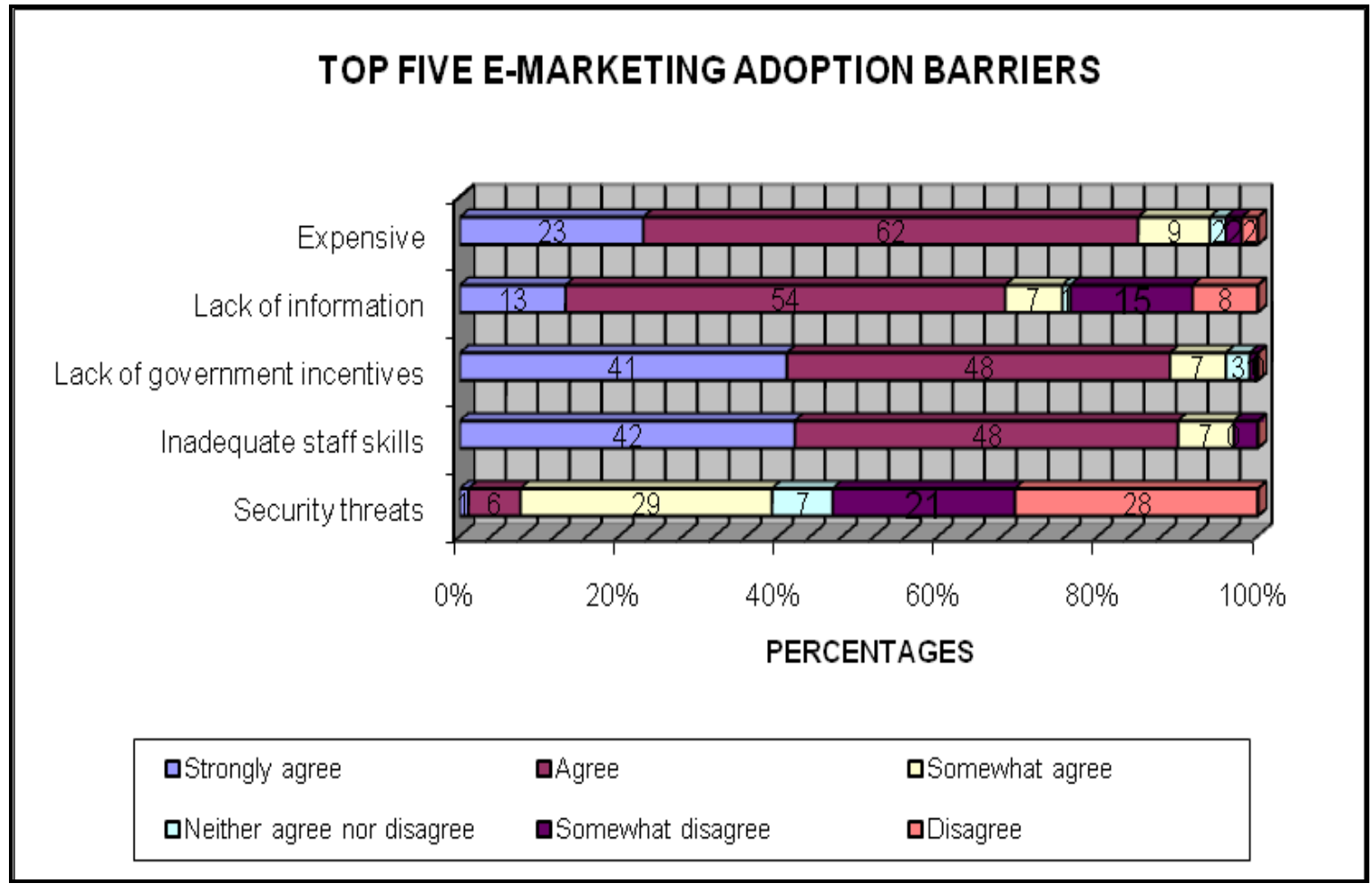

\section{Factor analysis}

In addition to obtaining the perceptions on the barriers to adoption of e-marketing a principal components factor analysis was conducted on the twenty-item scale to develop the set of factors that can be classified as barriers to adoption of e-marketing among SMEs. Prior to factor analysis the appropriateness of factorability on the data set was established. Examination of the correlation matrix (strength of linear association among variables) revealed that a substantial number $(75 \%)$ of the variables were $>0.30$ which according to Avkiran (1994:14) indicates factorability. The Kaiser-Meyer-Olkin (KMO) and the Bartlett's tests were also applied in order to further determine the appropriateness of the data set for factor analysis. The approximate chi-square was 827.888 with 120 degrees of freedom and significant at $p<0.000$. The KMO value was 0.618 which is considered satisfactory (Malhotra, 2007:615). Both test statistics inferred that factor analysis was justifiable for the data set.

The principal component analysis (initially unrotated) was applied, extracting factors with eigen values greater than one (Malhotra, 2007:617). This procedure extracted factors that were difficult to interpret. Factor analysis with Kaiser Normalisation (varimax rotation) was then applied in six iterations revealing a clearer factor structure with loadings ranging from 0.555 to 0.924 (only loadings of 0.50 were retained in the study). This is consistent with the guidelines of Uzoka et al. (2007:7) and Hair, Anderson, Tatham and Black (1992:239) who maintain that loadings of \pm 0.30 = minimum levels; $\pm 0.40=$ important levels and \pm 0.50 and greater are considered more important. 

N. Dlodlo
M. Dhurup

BARRIERS TO E-MARKETING ADOPTION AMONG SMALL AND MEDIUM ENTERPRISES (SMES) IN THE VAAL TRIANGLE

Item reduction was then undertaken by examining low factor loadings, multiple factor loadings and unstable item-total correlations. Subsequently, four variables were removed from the scale. The standardized alpha was recorded at 0.79 (Overall Cronbach $\alpha=0.79$ ) which exceeded the suggested level of 0.70 (Nunnally, 1978:245). Average inter-item correlations were recorded at 0.38 indicating satisfactory correlations among variables. To determine the number of factors to be extracted for use in the study the total percentage of variance was computed and accounted for $68.69 \%$ of the total variance in the data. Malhotra (2007:617) recommends that a satisfactory level is for the extracted factors to account for at least 60 percent of the total variance. Factors with eigen values of more than 1.0 were retained (eigen value $>1$ ) leading to the final extraction of five factors. Compilation of the scree plot further posited that the scree began to level off after five factors. The final factor structure is reflected in table 3.

Table 3: Rotated factor matrix and psychometric properties of the scale

\begin{tabular}{|c|c|c|c|c|c|c|c|}
\hline Variables & $\begin{array}{l}\text { Factor } \\
1\end{array}$ & $\begin{array}{l}\text { Factor } \\
2\end{array}$ & $\begin{array}{l}\text { Factor } \\
3\end{array}$ & $\begin{array}{l}\text { Factor } \\
4\end{array}$ & $\begin{array}{l}\text { Factor } \\
5\end{array}$ & $\begin{array}{l}\text { Item- to } \\
\text { total } \\
\text { correlation }\end{array}$ & $\begin{array}{l}\text { Alpha if } \\
\text { item } \\
\text { deleted }\end{array}$ \\
\hline E-marketing is too slow & .031 & .049 & .152 & .924 & .114 & .392 & .783 \\
\hline E-marketing is disorganized & .158 & .054 & .097 & .901 & .129 & .460 & .779 \\
\hline $\begin{array}{l}\text { E-marketing is not relevant to the SMEs line of } \\
\text { business }\end{array}$ & .758 & -.171 & .155 & .348 & .046 & .561 & .769 \\
\hline $\begin{array}{l}\text { E-marketing is not consistent with the size of } \\
\text { SMEs }\end{array}$ & .833 & .041 & .135 & .090 & -.002 & .574 & .768 \\
\hline $\begin{array}{l}\text { E-marketing is too difficult to manage and } \\
\text { control }\end{array}$ & .743 & .085 & .072 & -.103 & -.018 & .409 & .782 \\
\hline $\begin{array}{l}\text { E-marketing is only useful for young } \\
\text { businesses }\end{array}$ & -.005 & .002 & .020 & .223 & .811 & .169 & .799 \\
\hline $\begin{array}{l}\text { E-marketing is just a fashion, a mere buzz- } \\
\text { word }\end{array}$ & .144 & .036 & 128 & .037 & .832 & .269 & .791 \\
\hline Few of the business's customers are online & .212 & .056 & .831 & .206 & .001 & .552 & .770 \\
\hline Few of the business's competitors are online & .197 & -.017 & .879 & .133 & .020 & .510 & .773 \\
\hline Few of the business's suppliers are online & .068 & -.003 & .712 & -.018 & .104 & .309 & .791 \\
\hline SMEs do not know much about e-marketing & .243 & .722 & .159 & .052 & -.236 & .345 & .788 \\
\hline $\begin{array}{l}\text { SMEs lack advice from the government } \\
\text { authorities }\end{array}$ & .228 & .555 & .096 & 159 & -.342 & .303 & .789 \\
\hline SMEs lack training and support & -.038 & .813 & -.235 & .030 & .140 & .108 & .798 \\
\hline SMEs do not possess adequate staff skills in IT & .027 & .802 & .052 & -.051 & .227 & .260 & .791 \\
\hline $\begin{array}{l}\text { Our market is locally based so we do not need } \\
\text { e-marketing }\end{array}$ & 638 & .180 & .155 & -.089 & .175 & .444 & .780 \\
\hline $\begin{array}{l}\text { Our market does not know how to use e- } \\
\text { marketing }\end{array}$ & .625 & .203 & .092 & .233 & -.027 & .499 & .775 \\
\hline Eigenvalues & 4.11 & 2.23 & 1.83 & 1.44 & 1.36 & \multirow{4}{*}{\multicolumn{2}{|c|}{$\begin{array}{l}\text { Overall } \\
\alpha=0.79\end{array}$}} \\
\hline$\%$ of variance & 25.71 & 13.95 & 11.45 & 9.02 & 8.50 & & \\
\hline Cumulative \% & 25.71 & 39.67 & 51.13 & 60.15 & $\begin{array}{l}68.6 \\
8\end{array}$ & & \\
\hline Cronbach $\alpha$ & 0.80 & 0.70 & 0.78 & 0.88 & 0.71 & & \\
\hline
\end{tabular}




\section{DISCUSSION OF RESULTS}

The discussion of the results are summarized from the descriptive analysis of the top five inhibitors to emarketing adoption by SMEs and the factor extraction procedure described under the results section.

\section{SME barriers to e-marketing adoption}

The study revealed that the essential barriers to e-marketing adoption are:

- $\quad$ costs involved in the implementation of e-marketing,

- $\quad$ lack of information,

- $\quad$ lack of government incentives,

- $\quad$ lack of training,

- $\quad$ inadequate number of knowledgeable staff, and

- $\quad$ security threats.

These findings are consistent with studies conducted by other researchers on Internet non-adoption. Studies undertaken by Purcell and Toland (2004:250) for example, revealed that the determinants of Internet adoption in developing countries vary from those in developed nations. Findings of Uzoka et al. (2007:11) affirm that developing nations are mostly affected by factors relating to cost and availability of infrastructure, government support, and complexity of using the Internet as well as perceived benefits of the technologies. South African SMEs still find the cost of installation and maintenance too high compared with SMEs in developed countries (Cloete et al., 2006:5; Nannozi \& Coertzee, 2006:7). Ramsey and McCole (2005:538539) argued that those SMEs that did not adopt Internet marketing strategies due to the low level of management and business skills should try and acquire more training. Lack of training, capital and understanding of the potential benefits brought about by Internet technology have been cited as key barriers to the adoption of e-marketing by SMEs (Migiro \& Adigun, 2005:70). Other studies consider the lack of knowledge as a major barrier as it is associated with a lack of awareness; lack of advice and support or having a staff compliment without the necessary IT skills (Stansfield \& Grant, 2003:23; Kohn \& Husig, 2006:993).

Other researchers have highlighted the absence of a national and international regulatory framework related to privacy and security as a major concern for SMEs not adopting the Internet (Lewis \& Cockrill, 2002:199). Perceived risks of adopting Internet technology also act as a significant inhibitor. These risks include; privacy, authenticity of information about the products, unknown quality of products, fitting, size, originality of raw materials and policy about exchanges and returns (Jacobs \& De Klerk, 2003:11). In another study, Internet addiction, slow connections, Internet credit card theft and the receipt of undesired mail were cited as perceived inhibitors of adoption (Liebermann \& Stashevsky, 2002:292). A clear privacy policy can therefore, increase customer trust and confidence in an organisation's practises (Jordaan, 2004:10).

\section{Factor extraction on the barriers to e-marketing adoption}

These dimensions were named after a careful examination of the characteristics of the variables under each dimension. Barrier one comprised five variables loading onto it. It was labelled technology incompatibility with the target market and it accounted for 25.71 percent of the variance and the eigen value for the factor was 4.11. This component describes how a business' technology needs to be well-attuned to the adoption of e-marketing. Lack of congruence with the organisation's size, core activities and needs will ultimately lower the probability of an SME adopting e-marketing technology (Rogers, 1995:224). In addition, technologies should not be too complex to operate or maintain once they have been implemented (Harrison \& Waite, 2006:1004). These characteristics of technology are normally considered significant when explaining the rate and pattern of adoption. Combined with this barrier, is the critical absence of an eligible market that poses a challenge to SMEs in their quest to adopt e-marketing strategies (Lane et al., 2004:10). Respondents 
indicated that their product offerings are restricted to local boundaries (markets) and hence they find it difficult to take advantage of the opportunities offered by the geographically boundary-less forum offered through the e-marketing platform (Ramsey \& McCole, 2005:536).

The second barrier accounted for 13.95 percent of variance and with an eigen value of 2.23. This barrier was labelled lack of knowledge. The lack of skills, training, advice and adequate research around the topic of emarketing adoption has led many SMEs to fail to adopt e-marketing tools. These findings are consistent with studies of Ramsey and McCole (2005:539), and Kohn and Husig (2006:993) who state that the absence of experience and profound knowledge of e-marketing tools will often result in its non-adoption.

Barrier three comprised three variables and was labelled stakeholder un-readiness. It accounted for 11.45 percent of the variance and the eigen value for the factor was 1.83. This dimension incorporates the unwillingness of a business' stakeholders to operate online. E-marketing cannot be fully implemented if customers, suppliers and competitors are not prepared to trade on the same platform (Lee \& Cheung, 2004:388). This view suggests that SMEs are not prepared to adopt e-marketing as a serious business concept owing to the limited acceptance of online marketing practices by their business partners (Lane et al., 2004:10).

Barrier four was labelled technology disorientation. This barrier accounted for 9.02 percent of the total variance with an eigen value of 1.44 and had two variables loading onto it. The respondents described that the lack of orientation of e-marketing strategies is a challenge in their efforts to adopt online marketing strategies. Studies undertaken by Liebermann and Stashevsky (2002:292) also highlighted slow Internet connectivity as well as high levels of clutter on online forums as being significant inhibitors to e-marketing adoption.

The fifth barrier was labelled perceptions of e-marketing. This barrier accounted for 8.50 percent of the total variance with an eigen value of 1.36. This dimension describes the views and opinions that are preconceived in the minds of SME operators prior to disregarding e-marketing. Other organisations even view e-marketing as a mere catch phrase, with insignificant return on the amount of investment devoted to its adoption (Simpson \& Docherty, 2004:320).

Whilst Johnstone and Wright's (2004:228) ranking is in part encapsulated in this scale, only a few of the items were found to be efficacious within a South African context. This study lends support to the studies undertaken by Migiro and Adigun, (2005:70); Stansfield and Grant (2003:23); Kohn and Husig, (2006:993) that key barriers to the adoption of e-marketing vary according to countries.

Following on from the factor analysis procedure, the study progressed by providing an assessment of the reliability and validity of the research instrument.

\section{RELIABILITY}

The psychometric property of the scale, as measured by coefficient alpha (0.79), reflects an acceptable degree of cohesiveness among scale items and provides an indication of the extent to which a set of items are interrelated and internally consistent with each other. Table 3 presents the results of the reliability of the sub-scales. The reliability values ranged from 0.70 to 0.88 , with all factors satisfying the benchmark level of 0.70 as recommended by Nunnally (1978:245). 


\begin{abstract}
VALIDITY
Content validity refers to items used to measure a construct that are conceptually consistent with the definition of a variable (Scheepers, Bloom \& Hough, 2008:11). To ascertain content validity the instrument was refined during the pre-testing stage where a review of the questionnaire was undertaken by five academics in the Marketing and Information Technology environment after which several changes were made to the instrument. In addition, the questionnaire was pilot-tested with twenty SMEs to ensure that the variables clearly examined the marketing research problem. Discriminant validity was further assessed through the multivariate technique of factor analysis using Varimax rotation with Kaiser Normalisation. The Kaiser-Meyer-Olkin (KMO) measure of sampling adequacy and the Bartlett's test of Sphericity provided indications that the data was suitable for exploratory factor analysis. The eigen values, total percentage of variance and scree plot were used to determine the number of factors to be extracted. Those factors which loaded on two or more factors (cross-loadings) were deleted. This step of scale refinement assists in improving the validity of the research instrument to more satisfactory levels of discriminant validity i.e. all factors loading on only one factor with no cross-loadings (Dhurup \& Mohamane, 2007:69-70). The five barriers were identified by an iterative process of deleting items that did not load higher than 0.50 on any factor thus providing an assessment of construct validity (all factor loadings of at least 0.50 ).
\end{abstract}

\title{
RECOMMENDATIONS
}

In order to alleviate the barriers associated with the lack of knowledge and negative perceptions about emarketing, it is necessary that formal education and awareness tools be introduced starting from national level in order to avert scant adoption of e-marketing. E-marketing can rarely take off unless companies and individuals are educated about the opportunities offered by Internet related technologies (Stansfield \& Grant, 2003:25). Access to computers and the Internet is essential but not adequate without education and training in the effective use of these tools for marketing activities. Therefore, education and training should be initiated to increase the level of information and computer literacy amongst owners and managers of small businesses (O'Toole, 2003:120). This will also go a long way in dispelling negative perceptions that e-marketing is just a marketing buzz word. Stakeholder readiness was rated as the most relevant inhibitor of e-marketing adoption. It was established that many companies have adopted a 'wait-and-see' attitude toward the adoption of e-marketing strategies in the SME industry in South Africa (Cloete, 2006:8). As soon as successful champions emerge (innovators), many companies will be able seriously to consider participation. Furthermore, a lack of knowledge of the particular e-marketing strategies available leads SMEs to be partly ignorant of the particular benefits that can arise through the implementation of e-marketing. In this regard, emarketing adoption does not add value to businesses if the stakeholders to the small and medium sized businesses are not yet ready to participate on these electronic trading platforms. There is a need to encourage increased stakeholder participation in online marketing platforms, especially for intermediaries and customers through competitions with intermediaries and further education and training for customers and other critical stakeholders on the benefits and convenience of using electronic trading platforms.

Industry players should seek to strengthen the Internet capacities of SMEs through; nurturing e-marketing and examining the feasibility of a local/regional mechanism to promote information sharing and capacity building with a view to enhancing the efficiency and competitiveness of SMEs (Elliot \& Boshoff, 2007:15). This will go a long way in correcting the negative perceptions that SME operators have about the adoption of electronic marketing tools in various business practices.

Technology incompatibility, costs of implementation, perceptions and lack of eligible online markets were cited as barriers to e-marketing adoption within SMEs. These barriers and the insecurities brought about by 
the dot com crash of 2000; have inevitably reduced the popularity of adopting e-marketing strategies (Cloete, 2003:130). Further research needs to be conducted on how electronic innovations may be taken advantage of, for the benefit of marketing specifically within the small and medium business fraternity at both a local and national levels. This may be done by both academic and industry experts with a view to establishing relevant skills and techniques that may be needed to increase the efficiency of Internet marketing tools.

\section{LIMITATIONS OF THE STUDY}

This study adds to the body of knowledge and the growing literature on e-marketing adoption and its barriers. The limited sample size of 123 respondents used in this study indicates that caution is needed in the interpretation of these findings as these results cannot be accepted as completely relevant to other provinces in South Africa or to any other international SME scenarios. The study concentrated on SMEs operating within South Africa, a newly industrialised country, hence there is a possibility that measures of non-adoption in developing and newly industrialised nations may vary from those businesses operating in technologically advanced first world nations (developed countries). The study was conducted in one region only. In order to refine the results similar studies could be conducted in different provinces across South Africa.

It is also possible that there are similar or diverse barriers existing in e-marketing adoption both between SMEs within the same industry sector and between large and public enterprises. It is also important to note that while the five dimensions identified in this study are distinguished as having the greatest impact on emarketing technology non-adoption, other dimensions may also be important. Future studies with regards to the e-marketing adoption barriers in different organisational settings may provide new insights into adoption patterns.

\section{CONCLUSION}

The findings of this preliminary study do provide basic support for a five dimensional structure highlighting the inhibitors of electronic marketing adoption among SMEs in the Vaal Triangle namely, technology incompatibility with target markets; lack of knowledge; stakeholder unreadiness; technology disorientation as well as perceptions. These findings indeed concur with other studies that posit that the non-adoption of emarketing is multi-dimensional in its causality and that it largely depends on the business sector under investigation (Sparkes \& Thomas, 2001:332; Stansfield \& Grant, 2003:23; Kohn \& Husig, 2006:993). Marketing managers acknowledge that Internet marketing is effective. A study conducted by Singh (2002:8) suggests that organisations are clearly meeting the needs of some markets as Internet-based sales of \pm R21 million were generated in South Africa in December 2000. In this regard it may be concluded that a systematic implementation of e-marketing strategies is positively related to overall business success (Morikawo, 2004:174) and SMEs who do fail to implement these systems are set to jeopardize the potential returns of their businesses. 


\section{REFERENCES}

Avkiran NK. 1994. Developing an instrument to measure customer service quality in branch banking. The International Journal of Bank Marketing, 12(6):10-18.

Barry H \& Milner B. 2002. SMEs and E-Commerce; a departure from the traditional prioritisation of training? Journal of European Industrial Training, 26(7):316-326.

Bradley N. 2007. Marketing Research: tools \& techniques. Oxford : Oxford University Press.

Beheshti HM \& Sangari ES. 2007. The benefits of e-business adoption an empirical study of Swedish SMEs. Service Business Journal, 1(3):233-245.

Burgess SM \& Bothma CH. 2007. International Marketing. Cape Town: Oxford University Press.

Chaffey D \& Smith PR. 2005. E-marketing excellence; the heart of e-business. $2^{\text {nd }}$ ed. Oxford: Heinemann.

Chan C \& Swatman PMC. 2000. From EDI to E-Commerce: the BHP experience. Internet Research:

Electronic Networking Applications and Policy, 10(1):72-82.

Chaston I. 2000. Entrepreneurial Marketing; competing by challenging conventions. London: Macmillan Business Press.

Cloete E. 2003. SMEs in South Africa: Acceptance and adoption of E-Commerce. In Lubbe, S. \& Van Heerden, J.M. 2003. The Economic and Social Impacts of E-commerce. Hershey: Idea Group Publishers, pp. 121-134.

Cloete E. 2006. Aspects of E-Marketplaces in South Africa. Paper presented at the fourth International Science and Technology Conference held at the Vaal University of Technology on 28 to 30 November 2006.Vanderbijlpark, pp 1-27.

Coviello NE, Brodie RJ, Brookes RW \& Palmer RA. 2004. How managers perceive the impacts of information technologies on contemporary marketing practises: Reinforcing, Enhancing or Transforming. Journal of Relationship Marketing, 3(4):7-26.

Cronje GJ, Du Toit J \& Motlatla M. 2004. Introduction to Business Management. $6^{\text {th }}$ ed. Cape Town: Oxford Business Press.

De Vos AS, Strydom H, Fouche CB \& Delport CSL. 2002. Research at grassroots: for the social sciences and human service professions. $2^{\text {nd }}$ ed. Pretoria: Van Schaik Publishers.

Dhurup M \& Mahomane PBPL. 2007. Assessing internal marketplace relationships: measuring internal service quality within a petrochemical company. Southern African Business Review, 11(2):56-78.

Drew S. 2003. Strategic uses of E-Commerce by SMEs in the east of England. European Management Journal, 21(1):79-88.

Durkan P, Durkin M \& Dillen J. 2003. Exploring efforts to engender on-line trust. International Journal of Entrepreneurial Behaviour and Research, 9(3):93-110.

Elliot R \& Boshoff C. 2007. The influence of the owner-manager of small tourism businesses on the success of Internet Marketing. South Africa Small Business Journal, 38 (3):15-27.

Elliot R \& Sewry D. 2006. The influence of organisational factors in small tourism businesses on the success of Internet Marketing. South African Computer Journal, 37(1):41-50.

Falkena H. 2000. SMEs access to Finance in South Africa; a supply side regulatory review. Report by the task group of the policy board to financial services and regulations: Pretoria, Kluwer publishers.

Fillis I, Johannson U \& Wagner B. 2004. Factors impacting on e-business adoption and development in the smaller firm. International Journal of Entrepreneurial Behaviour and Research, 10(3):178-191.

Gilmore A, Gallagher D \& Henry S. 2007. E-Marketing and SMEs: operational lessons for the future. European Business Review, 19(3):234-247.

Gohary H. 2007. The effects of E-Marketing on the Marketing performance of Small Business Enterprises: a comparative study between Egypt and U.K. Paper presented at the $16^{\text {th }}$ EDAMBA Summer Academy held in France in July 2007. France, pp. 1-18.

Hair JF, Anderson RE, Tatham RL \& Black WC. 1992. Multivariate data analysis with readings. $3^{\text {rd }}$ ed. New York: McMillan Publishing Company. 
Hamill J 1997. The Internet and international marketing. International Marketing Review, 14(5):300-323.

Harris L \& Dennis C. 2002. Marketing the e-Business. London: Routledge Publishers.

Harrison T \& Waite K. 2006. A time based assessment of the influences, uses, and benefits of Intermediary website adoption. Journal of Information and Management, 43(1):1002-1013.

Hollenstein H. 2004. Determinants of the adoption of Information and Communication Technologies (ICT); an empirical analysis based on firm-level data for the Swiss business sector. Structural Change and Economic Dynamics, 15(3):315-342.

Jackson MLP. 2004. Entrepreneurial support in South Africa: a case study of a small enterprise support centre in Johannesburg. PhD. Thesis. Birmingham: University of Birmingham.

Jacobs BM \& De Klerk HM. 2003. Development of a socio-cognitive model for examining consumers' adoption of the Internet for the purchase of apparel. South African Journal of Information Management, 5(2):1-18.

Jeffcoat J, Chapell C \& Feindt S. 2002. Best practice in SME adoption of E-Commerce. An International Journal, 9(2):122-132.

Johnstone DA \& Wright L. 2004. The E-Business capability of small and medium sized firms in international supply chains. Information Systems and E-Business Management, 2:223-240.

Jordaan Y. 2004. Exploring and validating consumers' information privacy concerns. Management Dynamics, 15(2):2-12.

Jutla D, Bodorick P \& Dhaliwal J. 2002. Supporting the E-Readiness of small and medium sized enterprises: approaches and metrics. Internet Research: Electronic Networking Applications and Policy, 12(2):139-164.

Kalyanam K \& Mckintrye S. 2002. The E-Marketing mix: a contribution of the e-tailing wars. Journal of the Academy of Marketing Sciences, 30(4):463-495.

Kendall JD, Tung LL, Chua KH, Dennis NG CH \& Tan SM. 2001. Receptivity of Singapore's SMEs to electronic commerce adoption. Journal of Strategic Information Systems, 10:223-242.

Khan S. 2007. Adoption issues of Internet banking in Pakistani firms. Msc. Thesis. Lulei University of Technology.

Kohn S \& Husig S. 2006. Potential benefits, current supply, utilization and barriers to adoption: an exploratory study of German SMEs. Technovation, 26(1):988-998.

Lane MS, Van Der Vyver G, Delpachitra S \& Howard S. 2004. An electronic commerce initiative in regional

Sri Lanka: the vision for the central province electronic commerce portal. Electronic Journal of Information Systems in Developing Countries, 16(1):1-18.

Lee OKM \& Cheung CMK. 2004. Internet retailing adoption by small and medium sized enterprises (SMEs): a multiple case study. Information Systems Frontier, 6(4):385-397.

Lewis $\mathbf{R}$ \& Cockrill A. 2002. Going global- Remaining local. The impact of e-commerce on small retail firm in Wales. International Journal of Information Management, 22:195-209.

Liebermann Y \& Stashevsky S. 2002. Perceived risks as barriers to Internet and E-Commerce usage. Qualitative Market Research: an International Journal, 5(4):291-300.

Lloyd HR. 2002. Small and Medium Enterprises (SMEs): instruments of economic growth and development in a South African regional dispensation. Paper read at the annual conference of the European Regional Science Association held in Port Elizabeth on 2 to 6 August 2002:Port Elizabeth,pp1-25.

Maguire S, Koh SCL \& Magrys A. 2007. The adoption of E-Business and knowledge management in SMEs. Benchmarking: An International Journal, 14(1):37-58.

Malhotra NK. 2004. Marketing research: an applied orientation. Eaglewood Cliffs, NJ: Prentice- Hall.

Malhotra NK. 2007. Marketing research: an applied orientation. New Jersey,Upper Saddle River:PrenticeHall. 
Martin LM \& Matlay H. 2001. Blanket approaches to promoting ICT in small firms: some lessons from DTI ladder adoption model in UK. Internet Research: Electronic Networking Applications and Policy, 11(5):399410.

Matlay H \& Addis M. 2003. Adoption of e-commerce and ICT in small businesses: an HEI based consultancy perspective. Journal of Small Business and Enterprise Development, 10(3):321-335.

Migiro SO \& Adigun MO. 2005. ICTs, E -commerce and rural development: the case of arts and crafts SMEs in rural Kwazulu-Natal. Research Paper University of Zululand. 65-80, March.

Moodley S. 2002. Global market access in the Internet era: South Africa's wood furniture industry. Internet Research: Electronic Networking Applications and Policy, 12(1):31-42.

Morikawo M. 2004. Information technology and the performance of Japanese SMEs. Small Business Economics, 23:171-177.

Nannozi J \& Coertzee P. 2006. Factors hampering acceptance of ICT in SMEs. Paper presented at the fourth International Science and Technology Conference held at the Vaal University of Technology on 28 to 30 November 2006. Vanderbijlpark, pp 1-13.

Nunnally JC. 1978. Psychometric Theory. $2^{\text {nd }}$ ed. New York, NY: McGraw-Hill.

O'Toole T. 2003. E-Relationships-emergence and the small firm. Marketing Intelligence and Planning, 21(2):115-122.

Pearson MJ \& Grandon EE. 2004. Electronic commerce adoption: empirical study of small and medium sized US businesses. Journal of Information and Management, 42(1):197-216.

Poon S \& Swatman PMC. 1999. An exploratory study of small business Internet commerce issues. Journal of Information and Management, 35(1):9-18.

Porter M. 2001. Strategy and the Internet. Havard Business Review, 79(3):63-78.

Purcell F \& Toland J. 2004. Electronic commerce for the South Pacific: a review of E-readiness. Electronic Commerce Research, 4(1):241-262.

Ramsey E \& McCole P. 2005. E-Business in professional SMEs: the case of New Zealand. Journal of Small Business and Enterprise Development, 12(4):528-544.

Rao SS, Metts G \& Monge CAM. 2003. Electronic Commerce development in small and medium enterprises; a stage model and its implications. A Business Process Management Journal, 9(1):11-32.

Ramsey E \& Ibbotson I. 2006. E-Entrepreneurial SMEs: an Irish study of Micro and Macro influences. Journal of International Entrepreneurship, 3(1):317-332.

Republic of South Africa. 1995. Department of Trade and Industry. National Strategy for the Development and Promotion of Small Business in South Africa. Cape Town: Government Printer. (Notice 213 of 1995, 16317).

Republic of South Africa, 2009. Parliamentary Monitoring Group report; productivity SA, Unemployment Insurance Fund and Compensation Fund: Strategic Plans 2009-10, August 26.

Ryssen FJ. 2004. SMS Marketing: its place in mobile commerce and opportunity in the South African market. Acta Commercii, 4(1):48-59.

Rogers EM. 1995. Diffusion of innovations. $4^{\text {th }}$ ed. New York: Free Press publishers.

Sadowski BM, Maitland C \& Dongen JV. 2001. Strategic use of the Internet by small and medium-sized companies: an exploratory study. Journal of Information Economics and Policy, 14(1):75-93.

Scheepers MJ, Bloom JZ \& Hough J. 2008. The development of an instrument to assess the enacted environment for corporate entrepreneurship in South Africa. Management Dynamics, 17(4): 2-17.

Simpson M \& Docherty AJ. 2004. E-commerce adoption, support and advice for UK SMEs. Journal of Small Business and Enterprise Development, 11(3):315-328.

Singh MA. 2002. The Internet-Strategies for optimal utilization in South Africa. South African Journal of Information Management, 4(1):1-11. 
Sparkes A \& Thomas B. 2001. The use of the Internet as a critical success factor for the marketing of Welsh-agri food SMEs in the twenty first century. British Food Journal, 103(5):331-347.

Soontiens W. 2002. Managing International Trade: an analysis of South African SMEs and regional trade: Journal of Management Decisions, 40(7):710-719.

Stansfield M \& Grant K. 2003. An investigation into issues influencing the use of the Internet and electronic commerce among small-medium sized enterprises. Journal of Electronic Commerce Research, 4(1):15-33.

Taylor M \& Murphy A. 2004. SMEs and e-business. Journal of Small Business and Enterprise Development, 11(3):280-289.

Teo TSH \& Tan M. 1998. An empirical study of adopters and non-adopters of the Internet in Singapore. Journal of Information and Management, 34(1):339-345.

Upfold CT \& Sewry DA. 2006. An investigation of information security in small and medium enterprises in the Eastern Cape. Research paper. Grahamstown: Rhodes University.

Uzoka FME, Shemi AP \& Seleka GG. 2007. Behavioural influences of E-Commerce adoption in a developing country context. Electronic Journal of Information Systems in Developing Countries, 31(4):1-15.

Vuuren Van J J \& Groenewald D. 2007. A critical analysis of the influence of start-up factors in small businesses and entrepreneurial ventures in South Africa. Acta Commercii, 4(1): 269-280.

Wagener I. 2004. The building blocks of trust in Electronic commerce purchases: a case study. M.Comm. Dissertation. Johannesburg: RAU.

Walczuch R, Braven GV \& Lundgren H. 2000. Internet adoption barriers for small firms in the Netherlands. European Management Journal, 18(5):561-572.

Whiteley, D. 2000. E-commerce: strategy, technologies and applications. London: McGraw Hill.

Wrycza S \& Gajda D. 2007. Verification of E-business adoption models. Proceedings of the $16^{\text {th }}$ annual ISOnEworld Conference held in Las Vegas in May 2007. [Online]. Available at: < http:// www. Isoneworld.org>. Accessed: 20/04/2008.

Zaayman P. 2003. Functional Requirements of eCRM solutions for the South African SME sector. M.Phil. Dissertation. Johannesburg: RAU.

Zhao F. 2005. Entrepreneurship and innovations in e-business: an integrative perspective. International Journal of Entrepreneurship and Innovation, 6(1):53-60.

Zikmund WG. 1999. Essentials of Marketing Research. $6^{\text {th }}$. Orlando: The Dryden Press Publishers.

Zikmund WG. 2000. Exploring Market Research. $7^{\text {th }}$ ed. Orlando: The Dryden Press Publishers. 